\title{
Short Note \\ A Visual Basic program to plot sediment grain-size data on ternary diagrams ${ }^{2}$
}

\author{
L.J. Poppe ${ }^{\mathrm{a}, *}$, A.H. Eliason ${ }^{\mathrm{b}}$ \\ ${ }^{a}$ Coastal and Marine Geology Program, US Geological Survey, 384 Woods Hole Road, Woods Hole, MA 02543, USA \\ bliason Data Services, 230 Meetinghouse Road, Mashpee, MA 02649, USA
}

Received 30 October 2006; received in revised form 13 February 2007; accepted 7 March 2007

Keywords: Software; Program; Visual Basic; Data processing; Ternary diagrams; Sediment; Plotting

\section{Introduction}

Sedimentologic datasets are typically large and compiled into tables or databases, but pure numerical information can be difficult to understand and interpret. Thus, scientists commonly use graphical representations to reduce complexities, recognize trends and patterns in the data, and develop hypotheses. Of the graphical techniques, one of the most common methods used by sedimentologists is to plot the basic gravel, sand, silt, and clay percentages on equilateral triangular diagrams. This means of presenting data is simple and facilitates rapid classification of sediments and comparison of samples.

The original classification scheme developed by Shepard (1954) used a single ternary diagram with sand, silt, and clay in the corners and 10 categories to graphically show the relative proportions among these three grades within a sample. This scheme, however, did not allow for sediments with significant amounts of gravel. Therefore, Shepard's classification scheme was later modified by the

\footnotetext{
${ }^{25}$ Code available at http://www.iamg.org/CGEditor/index.htm.

*Corresponding author. Tel.: + 15084572314 ; fax: +15084572310 .

E-mail address: lpoppe@usgs.gov (L.J. Poppe).
}

addition of a second ternary diagram with two categories to account for gravel and gravelly sediment (Schlee, 1973). The system devised by Folk $(1954,1974)$ is also based on two triangular diagrams, but it has 21 categories and uses the term mud (defined as silt plus clay). Patterns within the triangles of both systems differ, as does the emphasis placed on gravel. For example, in the system described by Shepard, gravelly sediments have more than $10 \%$ gravel; in Folk's system, slightly gravelly sediments have as little as $0.01 \%$ gravel. Folk's classification scheme stresses gravel because its concentration is a function of the highest current velocity at the time of deposition as is the maximum grain size of the detritus that is available; Shepard's classification scheme emphasizes the ratios of sand, silt, and clay because they reflect sorting and reworking (Poppe et al., 2005).

The program described herein (SEDPLOT) generates verbal equivalents and ternary diagrams to characterize sediment grain-size distributions. It is written in Microsoft Visual Basic 6.0 and provides a window to facilitate program execution. The inputs for the sediment fractions are percentages of gravel, sand, silt, and clay in the Wentworth (1922) grade scale, and the program permits the user to select output in either the Shepard (1954) classification scheme, modified as described above, or the Folk 
(1954, 1974) scheme. Users select options primarily with mouse-click events and through interactive dialogue boxes. This program is intended as a companion to other Visual Basic software we have developed to process sediment data (Poppe et al., 2003, 2004).

\section{System requirements}

Windows 95/98/2000/XP computers with minimal specifications and the necessary support and associated files can run the compiled Visual Basic version of the program without difficulty. Users of this program with Windows 95 or early versions of Windows 98 may need to install updated versions of two support files into their C:/Windows/System directory. These files include the Common Dialog control file COMDLG32.OCX and the Visual Basic "Run-Time" driver MSVBVM60.DLL. Both support files are included with the software package available from the corresponding author, or, alternately, may be downloaded free from several sites on the Internet. ${ }^{1,2}$

\section{Program details}

The SEDPLOT code is available at http:// www.iamg.org/CGEditor/index.htm or by an anonymous ftp at the International Association for Mathematical Geology website. Compiled and uncompiled versions of the software and the necessary support files and documentation are available free of charge on a CD-ROM from the corresponding author. The program documentation, which is also available at the IAMG website above as an ASCII file, provides detailed information on use, options, and diagnostic considerations. The program may be executed by simply selecting (i.e., double clicking) the executable program (sedplot.exe) or its icon. Alternately, the program may be executed by clicking START, then RUN, and then typing the name of the program.

The program opens a Window that presents the user with several options (Fig. 1). First, the user can select an output scheme for classification and plotting: either the one modified from Shepard (1954), as modified by Schlee (1973), or that of Folk

\footnotetext{
${ }^{1}$ Microsoft Product Support Services, 2000. http://support. microsoft.com/default.aspx?

${ }^{2}$ WebAttack.com, 2002. http://www.webattack.com/help/ missingfiles.html.
}

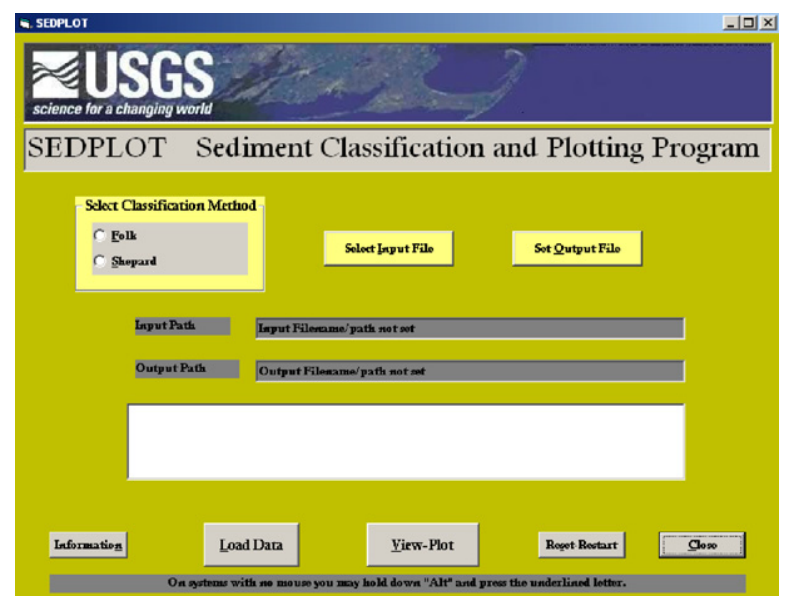

Fig. 1. Window for SEDPLOT program. User can select classification schemes, designate input and output files, start or cancel application, and access documentation. Clicking input and output file options opens text boxes that allow the user to enter file names and browse for destination directories.

(1954, 1974). Second, selecting the "Select Input File" button opens a text window allowing the user to identify the file to be processed and its location. The input file must be in comma-delimited ASCII text (.txt or .csv) and have seven fields that include: Sample Identifier, Latitude, Longitude, \%Gravel, $\%$ Sand, \%Silt, and \%Clay (Table 1A). The latitude and longitude fields may be left blank (i.e., not omitted, but comma delimited), but the remaining fields must be populated, and the sum of the percentages of gravel, sand, silt, and clay must total $100 \%( \pm 0.1 \%)$. The program expects the first line of the input file to be a header showing the attribute names; no embedded commas are allowed in any of the data fields.

Third, selecting the "Set Output File" button opens a text window that allows the user to name the file to be generated and to specify the destination directory. As the classification scheme, input file, and output file functions are successfully completed, the buttons change color from yellow to green. The program will not run unless an output file is selected, nor will the program allow identical input and output filenames and paths. If a file of the same name already exists in the destination directory, a window will open warning the user that the existing file will be replaced. If no destination directory is specified, the output file is written to the root directory $(\mathrm{C}: /)$. The text boxes beneath the "Select Input File" and "Set Output File" buttons on the main program Window are for display 
Table 1

Examples of input and output SEDPLOT files

\section{(A)}

SAMPLEID,LATITUDE,LONGITUDE, \%GRAVEL, \%SAND, \%SILT, \%CLAY

S1,40.437,-68.139,26.5,64.01,7.02,2.47

$\mathrm{S} 2,40.471,-68.33,55.34,30.39,10.89,3.39$

S3,40.487,-70.206,8.0,52.1,20.37,19.53

$\mathrm{S} 4,40.463,-67.705,0,60.45,28.59,10.96$

S5,40.174,-67.32201,0,50.69,25.19,24.12

$\mathrm{S} 6,, 0,84.6,11.3,4.1$

$\mathrm{S} 7,,, 0,12.33,46.82,40.85$

$\mathrm{S} 8,, 0,8.21,77.43,14.36$

$\mathrm{S} 9,, 0,4.66,84.31,11.03$

$\mathrm{S} 10,, 0,0,24.61,75.39$

$\mathrm{S} 11,, 0,2.89,40.32,56.79$

$\mathrm{S} 12,, 0,7.15,45.56,47.29$

$\mathrm{S} 13,,, 0,50,50,0$

$\mathrm{S} 14,,, 0,0,50,50$

$\mathrm{S} 15,, 0,33.34,33.33,33.33$

(B)

SAMPLEID,LATITUDE,LONGITUDE, \%GRAVEL, \%SAND, \%SILT,\%CLAY,SHEPARD_CLASS

S1,40.437,-68.139,26.5,64.01,7.02,2.47,GRAVELLY SEDIMENT

S2,40.471,-68.33,55.34,30.39,10.89,3.39,GRAVEL

S3,40.487,-70.206,8.0,52.1,20.37,19.53,SILTY SAND

S4,40.463,-67.705,0,60.45,28.59,10.96,SILTY SAND

S5,40.174,-67.32201,0,50.69,25.19,24.12,SAND SILT CLAY

S6, ,0,84.6,11.3,4.1,SAND

S7,,,0,12.33,46.82,40.85,CLAYEY SILT

S8, ,, $0,8.21,77.43,14.36$, SILT

S9,, $0,4.66,84.31,11.03$, SILT

$\mathrm{S} 10,,, 0,0,24.61,75.39, \mathrm{CLAY}$

S11,,0, $0,89,40.32,56.79$, SILTY CLAY

S12,,0, 7.15,45.56,47.29,SILTY CLAY

$\mathrm{S} 13,,, 0,50,50,0$, SILTY SAND

S14,,0,0,50,50,CLAYEY SILT

S15,,0,33.34,33.33,33.33,SAND SILT CLAY

(A) A typical input file with seven fields in comma-delimited ASCII. Fields must be in this order, but population of navigation fields is optional. Note that the last 10 records have no navigation. (B) Output file generated from input file with Shepard (1954) option selected. Note the eighth field for sediment classification generated in the output file.

purposes only, allowing the user to confirm which paths and filenames have been selected using the buttons. Input and output filenames and paths cannot be manually entered using these boxes.

Selecting the "Load Data" command button executes the data processing. The program generates the output file in the requested destination directory and allows the user to view results in a display window to determine whether errors have occurred. The output file, which is identical to that generated by the program SEDCLASS (Poppe et al., 2003), also has a header for its first line, but now contains eight fields; the original fields plus an additional field for sediment classification in the desired scheme (Table 1B). If the percentages of the various size fractions do not total 100\% $( \pm 0.01 \%)$, the program will continue, but a cumulative frequency percent error message (ERROR CFP NOT $100 \%$ ) appears in the classification field for that record. If an input record contains too few fields, the program will continue, but a record will be written containing the Sample Identifier (if available), null fields, and an error message (ERROR. INPUT RECORD FORMAT) in the classification field. If an input record contains more than seven fields, those extra fields will be ignored. If the input file has a header record containing more than seven fields, the user is warned that they may have selected an output file. Blank records result in a fatal runtime error aborting the program. 
Selecting the "View-Plot" command button opens a second window showing the ternary diagram of the currently selected classification scheme and a set of control buttons and interfaces (Figs. 2 and 3). The "Plot Data Array" button initiates plotting to the current window of the data loaded from the main window. The "Clear Plot" clears the ternary diagram of all data, but does not erase the diagram.

A button that alternates between "Show FINE Plot" and "Show COARSE Plot" erases the plotted
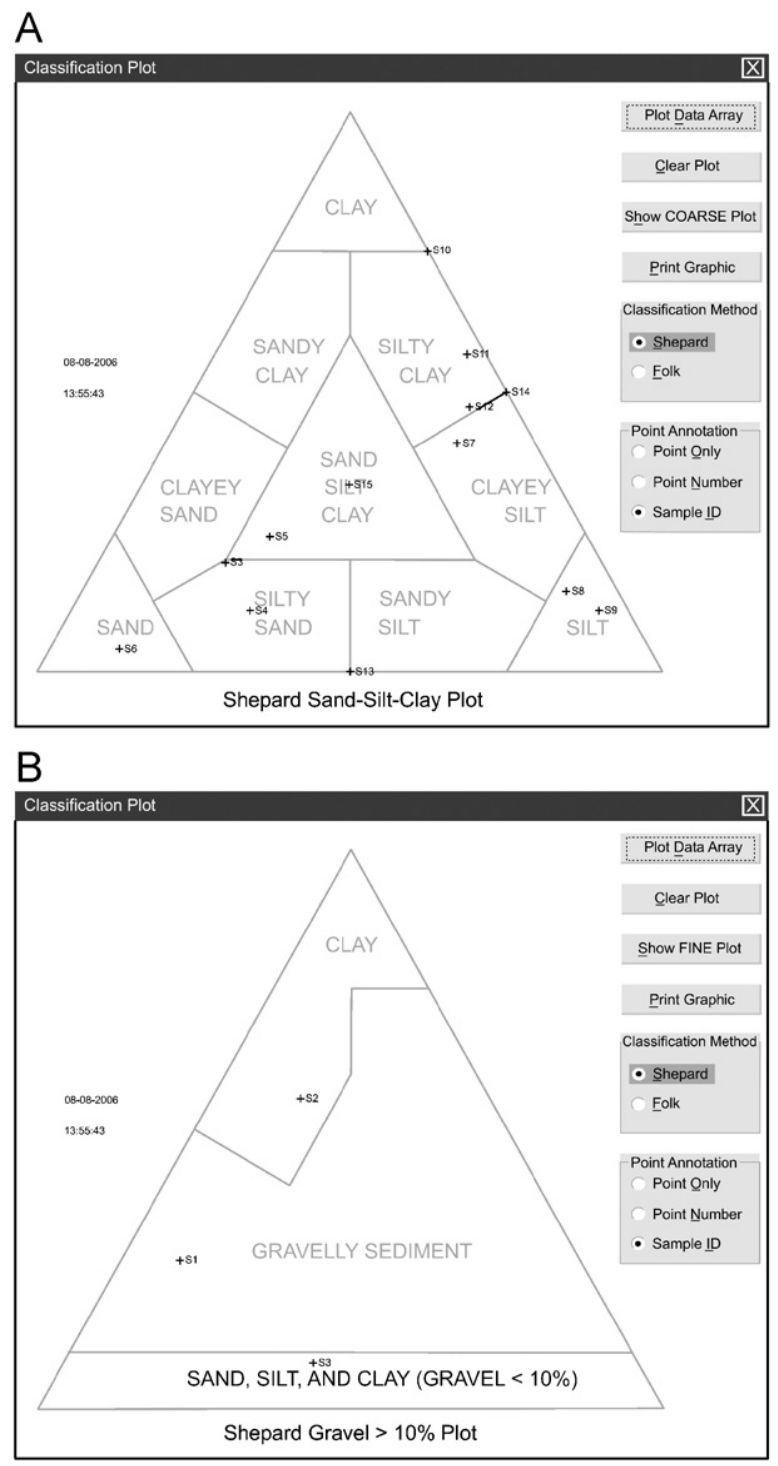

Fig. 2. Ternary diagrams of sediment classification scheme from Shepard (1954) and modified by Schlee (1973), produced by program SEDPLOT. (A) Samples with no gravel. (B) Samples with gravel. Data plotted are from the input file provided in Table 1 .
A

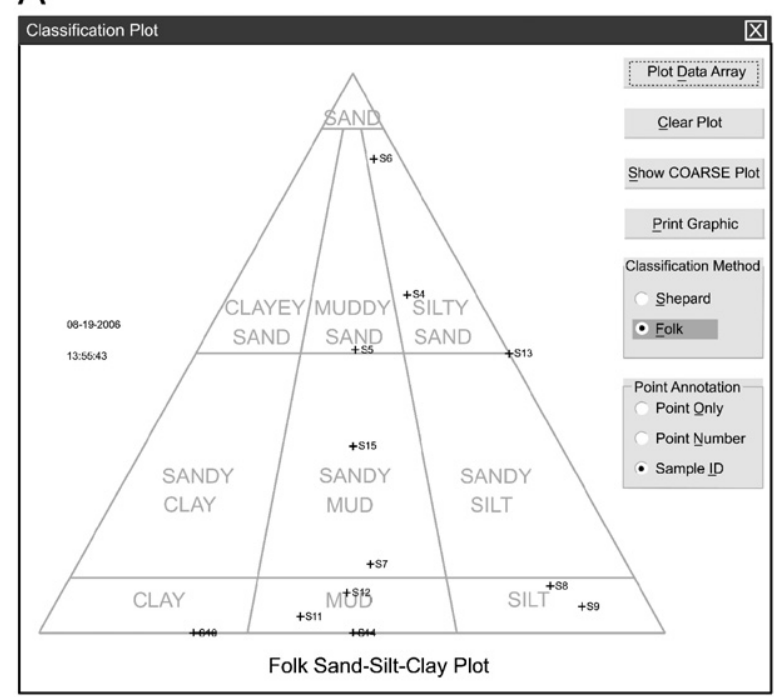

B

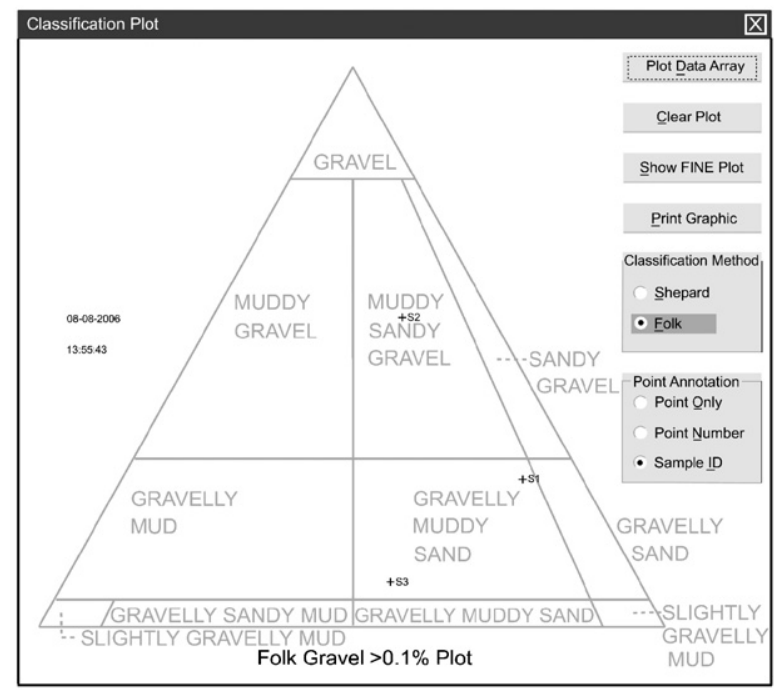

Fig. 3. Ternary diagram of sediment classification scheme from Folk (1954, 1974), produced by program SEDPLOT. (A) Samples with no gravel. (B) Samples with greater than $0.1 \%$ gravel. Data plotted are from the input file provided in Table 1.

data and toggles between the fine or coarse ternary diagram for the selected classification scheme. Fine plots are for samples composed primarily of sand, silt, and clay; coarse plots are for samples having significant gravel. Significant gravel is defined by Folk (1974) as $>0.01 \%$, but as $>10 \%$ by Shepard (1954). The "Plot Data Array" button must be selected again after this command to repopulate the graphic. The "Print Graphic" button prints the current plot window to whatever printer is active as the current system printer for this computer. The 
printer must have typical MS Windows graphics printing capability.

The "Classification Method" interface has two radio buttons that allow the user to toggle between the ternary diagrams of Folk (1974) or Shepard (1954). The screen graphic will clear and replot the selected ternary diagram for the currently selected size fraction. The "Plot Data Array" button must be re-selected after this command to repopulate the diagram. The "Point Annotation" interface has three radio buttons that allow the user to choose annotation of the plotted points. The plotted points are plus signs $(+)$ plotted with their centers at the points of closest available proximity to the actual point coordinates. Annotation options are: point only, point number (i.e., the number of the record in the data file), or the station identifier from the first field of the data record. Changing this option does not change the plotted data. The "Clear Plot" and, subsequently, "Plot Data Array" buttons must be re-selected after this command to repopulate the graphic.

In the event that the user desires to observe the data associated with a given point, it is only necessary to click on the main screen and scroll to the corresponding point in the data window. The user may return to the plot screen without destruction of the plotted data. Additional datasets may also be added to an existing plot, thereby allowing the user to compare and distinguish between their distributions. This is accomplished by rerunning the program without selecting the Clear Plot button or closing the plot window. When the Plot Data Array button is now pressed, the new dataset will be added to the existing plot. If a user wishes to read an output file as an input file, it is only necessary to remove the eighth field of the header record.

Selecting the "Reset-Restart" button restarts the program; selecting the "Information" button allows the user to view schematics of the classification systems, output files, and the documentation; and clicking "Close" exits the program and closes the window. On systems with no mouse, the user can hold down the "Alt" button key and press the underlined character of the desired function. We have tested the program to 1200 records.

\section{Acknowledgments}

We thank Bill Waite, Brian Buczkowski, and Jim Robb (all USGS) for their thoughtful reviews, and the Coastal and Marine Geology Program of the US Geological Survey for its financial support. Although this program has been used by the USGS and Eliason Data Services, no warranty is expressed or implied. Any use of trade, product, or firm names is for descriptive purposes only and does not imply endorsement by the US Government.

\section{Appendix A. Supplementary materials}

Supplementary data associated with this article can be found in the online version at doi:10.1016/ j.cageo.2007.03.019

\section{References}

Folk, R.L., 1954. The distinction between grain size and mineral composition in sedimentary rock nomenclature. Journal of Geology 62 (4), 344-359.

Folk, R.L., 1974. Petrology of Sedimentary Rocks. Hemphill Publishing Co., Austin, TX, 182pp.

Poppe, L.J., Eliason, A.H., Hastings, M.E., 2003. A Visual Basic program to classify sediments based on gravel-sand-silt-clay ratios. Computers \& Geosciences 29, 805-809.

Poppe, L.J., Eliason, A.H., Hastings, M.E., 2004. A Visual Basic program to generate grain-size statistics and to extrapolate particle distributions. Computers \& Geosciences 30, 791-795.

Poppe, L.J., Williams, S.J., Paskevich, V.F., 2005. USGS eastcoast sediment analysis: procedures, database, and GIS data. US Geological Survey Open-File Report 2005-1001, DVDROM.

Schlee, J.S., 1973. Atlantic continental shelf and slope of the United States - sediment texture of the northeastern part. US Geological Survey Professional Paper 529-L, 64pp.

Shepard, F.P., 1954. Nomenclature based on sand-siltclay ratios. Journal of Sedimentary Petrology 24 (3), 151-158.

Wentworth, C.K., 1922. A scale of grade and class terms for clastic sediments. Journal of Geology 30, 377-392. 